\title{
2018 Chilean Physical Activity Report Card for Children and Adolescents: Full Report and International Comparisons
}

\author{
Nicolas Aguilar-Farias, Sebastian Miranda-Marquez, Pia Martino-Fuentealba, Kabir P. Sadarangani, \\ Damian Chandia-Poblete, Camila Mella-Garcia, Jaime Carcamo-Oyarzun, Carlos Cristi-Montero, \\ Fernando Rodriguez-Rodriguez, Pedro Delgado-Floody, Astrid Von Oetinger, Teresa Balboa-Castillo, \\ Sebastian Peña, Cristobal Cuadrado, Paula Bedregal, Carlos Celis-Morales, \\ Antonio Garcia-Hermoso, and Andrea Cortínez-O’Ryan
}

\begin{abstract}
Background: The study summarizes the findings of the 2018 Chilean Report Card (RC) on Physical Activity (PA) for Children and Adolescents and compares the results with the first Chilean RC and with other countries from the Global Matrix 3.0. Methods: A Research Work Group using a standardized methodology from the Global Matrix 3.0 awarded grades for 13 PA-related indicators based on the percentage of compliance for defined benchmarks. Different public data sets, government reports, and papers informed the indicators. Results: The grades assigned were for (1) "behaviors that contribute to overall PA levels": overall PA, D-; organized sport participation, D-; active play, INC; and active transportation, F; (2) "factors associated with cardiometabolic risk": sedentary behavior, C-; overweight and obesity, F; fitness, D; sleep, INC; and (3) "factors that influence PA": family and peers, F; school, D; inclusion, INC; community and built environment, B; government strategies and investments, B-. Conclusions: Chile's grades remained low compared with the first RC. On the positive side, Chile is advancing in environmental and policy aspects. Our findings indicate that the implementation of new strategies should be developed through collaboration between different sectors to maximize effective investments for increasing PA and decreasing sedentary time among children and adolescents in Chile.
\end{abstract}

Keywords: screen time, physical inactivity, outdoor time, active play

Physical inactivity is a global and multifactorial problem that is affecting all ages. ${ }^{1-3}$ Most countries, including Chile, are taking actions through policies to address this issue., ${ }^{4,5}$ As the lack of

Aguilar-Farias, Miranda-Marquez, Martino-Fuentealba, Chandia-Poblete, MellaGarcia, Carcamo-Oyarzun, Delgado-Floody, and Cortínez-O'Ryan are with the Department of Physical Education, Sports and Recreation, Universidad de La Frontera, Temuco, Chile. Aguilar-Farias, Miranda-Marquez, Martino-Fuentealba, Chandia-Poblete, Mella-Garcia, and Cortínez-O'Ryan are also with the UFRO Activate Research Group, Universidad de La Frontera, Temuco, Chile. Sadarangani is with the Universidad Autonoma de Chile, Santiago, Chile; and the School of Physiotherapy, Universidad Diego Portales, Santiago, Chile. Cristi-Montero and Rodriguez-Rodriguez are with the IRyS Group, Physical Education School, Pontificia Universidad Catolica de Valparaiso, Valparaiso, Chile. Von Oetinger is with the School of Physiotherapy, Universidad San Sebastian, Santiago, Chile; and the Postgraduate Direction, Universidad Mayor, Santiago, Chile. Balboa-Castillo is with the Department of Public Health, Universidad de La Frontera, Temuco, Chile; and the Center for Research in Cardiometabolic and Nutritional Epidemiology (EPICYN), Universidad de La Frontera, Temuco, Chile. Peña is with the Department of Public Health Solutions, Finnish Institute for Health and Welfare, Helsinki, Finland; and the Faculty of Medicine, Universidad Diego Portales, Santiago, Chile. Cuadrado is with the Health Policy, Systems and Management Program, School of Public Health, Universidad de Chile, Santiago, Chile. Bedregal is with the Department of Public Health, Pontificia Universidad Catolica de Chile, Santiago, Chile. Celis-Morales is with the Center of Exercise Physiology, Universidad Mayor, Santiago, Chile. Garcia-Hermoso is with the Laboratory of Physical Activity Sciences, Sports and Health, Universidad de Santiago, Santiago, Chile; and the Navarrabiomed, Complejo Hospitalario de Navarra (CHN), Universidad Pública de Navarra (UPNA), IdiSNA, Pamplona, Spain. Cortínez-O'Ryan is also with the School of Kinesiology, Faculty of Medical Sciences, Universidad de Santiago de Chile, Santiago, Chile. Aguilar-Farias (nicolas.aguilar@ufrontera.cl) is corresponding author. physically active people is alarming in most countries, the World Health Organization has released the Global Action Plan for Physical Activity to set principles and guidance to global and regional actions. ${ }^{6}$ The Global Action Plan for Physical Activity has stated that surveillance and collaborative research are highly relevant to help to develop effective strategies. Also, the Global Action Plan for Physical Activity has made a call for including a system approach to understand and implement actions in different settings and levels. ${ }^{7}$ Along those lines, the Active Healthy Kids Global Alliance, an international initiative of researchers, has coordinated and released 3 global reports of indicators related to physical activity (PA), the Global Matrix on PA for Children and Youth. ${ }^{8-10}$

Chile has participated in the Active Healthy Kids Global Alliance since 2014 for the preparation and release of the Global Matrix 2.0 in $2016 .{ }^{9}$ In the first Chilean Report Card (RC) on PA for Children and Adolescents, released in 2016, overall PA was graded with an F, as only 3 out of 10 children and 2 out of 10 adolescents performed at least 60 minutes of moderate to vigorous PA per day. ${ }^{11}$ Also, most indicators failed, except for community and environment, and government strategies and investments. Unfortunately, Chile was among those countries with worse indicators.

In this last Global Matrix of PA, ${ }^{10} 49$ countries from all continents and very diverse Human Development Indices (HDI) were included. ${ }^{12-14}$ In 2018, unlike previous versions of the Global Matrix, only a short version of their reports were requested from the participating countries, which included the assigned grades, which allowed comparisons for the Global Matrix 3.0. This article constitutes the extended version of the shortened version already published, ${ }^{15}$ detailing the criteria adopted to rate each domain, in addition to offering an analysis of Chile in an international 
context, taking advantage of the information provided by the already published Global Matrix 3.0.

\section{Methods}

The UFRO Activate Research Group at the Universidad de La Frontera organized and coordinated a Research Work Group (RWG) for the development of the second Chilean RC on PA in Children and Adolescents. The RWG consisted of 18 PA researchers from 9 academic organizations. An advisory and collaborative committee was also formed from participants of the public sector: Ministry of Health, Ministry of Sports, and Junta Nacional de Auxilio Escolar y Becas. Members of the RWG performed the systematic data search and assessment, while the advisory and collaborative committee assisted in providing updated information on current surveillance data to request access for custom analyses and feedback about grades.

The RWG based the structure of the current report on the design of previous RCs. ${ }^{8,9}$ The 2018 Chilean RC included the following 10 core PA indicators that are common to the Global Matrix 3.0: overall PA, ${ }^{10}$ organized sports participation, active play, active transportation, sedentary behavior, physical fitness, family and peers, school, community and the built environment, and government. Also, we have included 3 additional indicators: sleep, inclusion, and overweight and obesity.

The members of the RWG were organized in subgroups for each indicator, to conduct a systematic search and literature review of published and unpublished data, such as public data sets, national surveys, academic papers, and government documents, from the second half of 2015 to the first half of 2018, except for the new indicators, in which data from 2008 were reviewed. The advisory and collaborative committee assisted in locating additional information and access to complementary data, and provided guidance about the appropriateness of some questions from national surveys that may contribute to the RC indicators. When necessary, members of the RWC asked formally, through the transparency website of the Chilean Government (www.portaltransparencia.cl), for public data sets when these were not accessible directly from the systematic search. A collaborative approach was used between the subgroups, as when identified the RWG members shared key articles (ie, national or local government reports) and complementary sources (ie, databases). Evidence selection and its consequent assessment were based on aspects such as representativeness of the data (eg, national vs regional/local based), how the sample was obtained (ie, sampling frame/procedure and response rate), the age range of the children surveyed (5-17 y old), the sample size obtained, the quality of the data metric (eg, how the question was asked, objective vs subjective, reliability and validity data), and reporting on specific subgroups (eg, sex, age, socioeconomic status). ${ }^{16}$ Then, each subgroup summarized the evidence and assigned the grades to be discussed with the RWG.

The primary data sources were the Programme for International Student Assessment (PISA 2015), ${ }^{17}$ Survey of Activities in Children and Adolescents (EANNA 2012), ${ }^{18}$ Global School-based Student Health Survey (GSHS 2013), ${ }^{3}$ National Survey of Quality of Life (ENCAVI 2015-2016), ${ }^{19}$ Survey of Perception of Urban Quality of Life (EPCVU 2015), ${ }^{20}$ National Survey of Physical Education (ENEF 2015), ${ }^{21}$ Nutritional Map (JUNAEB 2017), ${ }^{22}$ National Health Survey (ENS 2016-2017), ${ }^{23}$ National Survey of Vulnerability (EV 2017), ${ }^{24}$ and National Urban Survey of Citizen Safety (ENUSC 2016). ${ }^{25}$ The data from regional studies conducted in Chile were also included to highlight local efforts and assess regional trends and differences.
The grading process for each indicator was based on criteria from other RCs, ${ }^{9,26,27}$ but other criteria were included to provide a comprehensive assessment and include new indicators. For example, for overall PA levels, not only the prevalence of children and adolescents meeting WHO PA guidelines was considered, but also gender disparities in PA levels. Each criterion was assessed individually and contributed to the final grade for each indicator. The final grade for each criterion and indicator was based on the percentage of children and adolescents meeting a defined benchmark, as presented in Table 1 . The RWG used an international letter grading system (A-F) for allowing comparisons of indicators between countries, but also adapted this grading system to the Chilean numerical system (1-7) to allow national pertinence (Table 2).

The dissemination and media strategy through a website (www.chileactivate.cl), social networks (Facebook and Twitter), printed materials, and press releases were developed by the UFRO Activate Research Group with collaboration from the UFRO Communications Office (DIRCOM) at the Universidad de La Frontera.

\section{Results and Discussion}

The 2018 Chilean RC, framed within the Global Matrix 3.0, is the second effort to provide updated evidence, based on published and unpublished local evidence, that aims to reflect on how the country is supporting children and adolescents to be physically active and how they are responding regarding PA-related behaviors and PA-related health outcomes.

Overall, the highest grades were observed for 2 sources of influence: community and environment (B) and government (B-; Table 2). PA-related behaviors received low grades ( $\mathrm{F}$ for active transportation and D for overall PA), as did overweight and obesity (F). It would be expected that relatively high grades for environmental and political sources of influence would positively impact PA-related behaviors, but this association was not reflected in these grades. This phenomenon is aligned with other countries of the very high HDI group, where the grades for government, community and environment, and school averaged $\mathrm{C}+, \mathrm{B}-$, and $\mathrm{C}+$, respectively, while the PA-related behaviors, such as overall PA, active play, and sedentary behavior domains scored lower (D-, D+, and D+, respectively). ${ }^{12}$ Only one out of 10 core indicators selected for the Global Matrix 3.0 was assigned a grade of INCOMPLETE (active play), while 2 out of 3 noncore indicators (sleep and inclusion) fall within this category, as there were not enough data. The rationale for each grade is presented in Tables 1 and 2 .

The Global Matrix 3.0 gathered the other $48 \mathrm{RCs}$, accounting for 490 grades grouped in the 10 core domains. ${ }^{10}$ Since this study was recently published, we will present the Chilean grades for each domain with the criteria used for assigning them, along with summarized results of other countries' results to provide a broader understanding within a global context and an enriched discussion.

\section{Overall PA}

The grade "D-" for overall PA levels in children and adolescents was based on the following 4 criteria: (1) the weighted average of $20.2 \%$ of children and adolescents meeting the PA guidelines, $3,17,18$ (2) $27.4 \%$ of children (9-11 y old) and $18.9 \%$ of adolescents meet the PA guidelines based on national data, ${ }^{3,17,18}$ (3) there is lack of data for 5- to 8-year-olds, and (4) most data were collected in regional capitals, limiting extrapolation to other cities or towns within Chile. Regarding the global context, $30 \%$ of the countries 
Table 1 Indicators and Benchmarks Used to Guide the Grade Assignment Process ${ }^{10}$

\begin{tabular}{|c|c|}
\hline Indicator & Benchmark \\
\hline Overall PA & $\begin{array}{l}\% \text { of children and youth who meet the Global Recommendations on Physical Activity for Health, which recommends } \\
\text { that children and youth accumulate at least } 60 \mathrm{~min} \text { of moderate- to vigorous-intensity PA per day on average. }\end{array}$ \\
\hline Organized sport participation & $\%$ of children and youth who participate in organized sport or PA programs. \\
\hline Active play & $\begin{array}{l}\% \text { of children and youth who engage in unstructured/unorganized active play at any intensity for more than } 2 \mathrm{~h} / \mathrm{d} \text {. } \\
\% \text { of children and youth who report being outdoors for more than } 2 \mathrm{~h} / \mathrm{d} \text {. }\end{array}$ \\
\hline Active transportation & $\%$ of children and youth who use active transportation to get to and from places (eg, school, park, mall, friend's house). \\
\hline Sedentary behavior & $\begin{array}{l}\% \text { of children and youth who meet the Canadian Sedentary Behavior Guidelines ( } 5-17 \text { y old: no more than } 2 \mathrm{~h} \text { of } \\
\text { recreational screen time per day). Note: The guidelines currently provide a time limit recommendation for screen- } \\
\text { related pursuits, but not for non-screen-related pursuits. }\end{array}$ \\
\hline Physical fitness & $\begin{array}{l}\text { Average percentile achieved on specific physical fitness indicators based on the normative values published by } \\
\text { Tomkinson et al. } .^{37}\end{array}$ \\
\hline Sleep & $\begin{array}{l}\% \text { of children and youth who meet the Canadian Sleeping Guidelines: } 9-11 \mathrm{~h} \text { of sleep/night for children aged 5-13 y } \\
\text { old, and } 8-10 \mathrm{~h} \text { of sleep/night for children } 14-17 \text { y old. }\end{array}$ \\
\hline Overweight and obesity & $\%$ of children and youth who are overweight or obese. \\
\hline Inclusion & $\begin{array}{l}\text { Two benchmarks for } 3 \text { specific groups were assessed: (1) children with disability, (2) immigrant children, and } \\
\text { (3) children from indigenous ethnic groups. } \\
\% \text { who meet the Global Recommendations on Physical Activity for Health. } \\
\% \text { who participate in organized sport or PA programs. }\end{array}$ \\
\hline Family and peers & $\begin{array}{l}\% \text { of family members (eg, parents, guardians) who facilitate PA and sport opportunities for their children } \\
\text { (eg, volunteering, coaching, driving, paying for membership fees and equipment). } \\
\% \text { of parents who meet the Global Recommendations on Physical Activity for Health, which recommends that adults } \\
\text { accumulate at least } 150 \text { min of moderate-intensity aerobic PA throughout the week or do at least } 75 \text { min of vigorous- } \\
\text { intensity aerobic PA throughout the week or an equivalent combination of moderate- and vigorous-intensity PA. } \\
\% \text { of family members (eg, parents, guardians) who are physically active with their kids. } \\
\% \text { of children and youth with friends and peers who encourage and support them to be physically active. } \\
\% \text { of children and youth who encourage and support their friends and peers to be physically active. }\end{array}$ \\
\hline School environment & $\begin{array}{l}\% \text { of schools with active school policies (eg, daily physical education, daily PA, recess, "everyone plays" approach, } \\
\text { bike racks at school, traffic calming on school property, outdoor time). } \\
\% \text { of schools where the majority }(\geq 80 \%) \text { of students are taught by a physical education specialist. } \\
\% \text { of schools where the majority ( } \geq 80 \%) \text { of students are offered the mandated amount of physical education (for the } \\
\text { given state/territory/ region/country). } \\
\% \text { of schools that offer PA opportunities (excluding physical education) to the majority ( }>80 \% \text { ) of their students. } \\
\% \text { of parents who report that their children and youth have access to PA opportunities at school in addition to physical } \\
\text { education classes. } \\
\% \text { of schools with students who have regular access to facilities and equipment that support PA (eg, gymnasium, } \\
\text { outdoor playgrounds, sporting fields, multipurpose space for PA, equipment in good condition). }\end{array}$ \\
\hline Community and environment & $\begin{array}{l}\% \text { of children or parents who perceive that their community/municipality is doing a good job at promoting PA } \\
\text { (eg, variety, location, cost, quality). } \\
\% \text { of communities/municipalities that report that they have policies promoting PA. } \\
\% \text { of communities/municipalities that report that they have infrastructure (eg, sidewalks, trails, paths, bike lanes) } \\
\text { specifically geared toward promoting PA. } \\
\% \text { of children or parents who report having facilities, programs, parks, and playgrounds available to them in their } \\
\text { community. } \\
\% \text { of children or parents who report living in a safe neighborhood where they can be physically active. } \\
\% \text { of children or parents who report having well-maintained facilities, parks, and playgrounds in their community that } \\
\text { are safe to use. }\end{array}$ \\
\hline $\begin{array}{l}\text { Government strategies and } \\
\text { investments }\end{array}$ & $\begin{array}{l}\text { Evidence of leadership and commitment in providing PA opportunities for all children and youth. Allocated funds and } \\
\text { resources for the implementation of PA promotion strategies and initiatives for all children and youth. Demonstrated } \\
\text { progress through the key stages of public policy making (ie, policy agenda, policy formation, policy implementation, } \\
\text { policy evaluation, and decisions about the future). }\end{array}$ \\
\hline
\end{tabular}

Abbreviation: PA, physical activity. Note: The indicators of sleep, overweight and obesity, and inclusion were not included in the Global Matrix 3.0.

also scored D. However, $40 \%$ scored higher grades than Chile, with Slovenia holding the highest grade $(\mathrm{A}-) .{ }^{10}$

\section{Organized Sport Participation}

The grade of "D-" or " 2.5 " for participation in organized sports was based on the following 3 main criteria: (1) percentage of participation in organized sports that ranged from $14.4 \%$ to $26.3 \%$ in children and adolescents aged 5-17 years old ${ }^{18,24}$; (2) a higher proportion of boys reported participation in sports compared with girls across all age groups, especially in younger and older ages ${ }^{18}$; and (3) participation in one of the main programs of the Ministry of Sports for children and adolescents from 4 to 14 years old ("Comprehensive Sports Schools") decreased by 0.4\% from 2016 (186,353 children) to 2017 (185,788 children). ${ }^{29}$ 
Table 2 Grades Comparison Between Report Card 2016 and 2018

\begin{tabular}{|c|c|c|c|c|}
\hline \multirow[b]{2}{*}{ Indicator } & \multicolumn{2}{|c|}{2016 grade } & \multicolumn{2}{|c|}{2018 grade } \\
\hline & $\begin{array}{c}\text { International grading } \\
\text { system }\end{array}$ & $\begin{array}{c}\text { Chilean grading } \\
\text { system }\end{array}$ & $\begin{array}{c}\text { International grading } \\
\text { system }\end{array}$ & $\begin{array}{c}\text { Chilean grading } \\
\text { system }\end{array}$ \\
\hline Overall PA & $\mathrm{F}$ & 2 & D- & 2.5 \\
\hline Organized sport participation & $\mathrm{D}$ & 3 & D- & 2.5 \\
\hline Active play & INC & INC & INC & INC \\
\hline Active transportation & $\mathrm{C}-$ & 3 & $\mathrm{~F}$ & 2 \\
\hline Sedentary behavior & $\mathrm{D}$ & 3 & $\mathrm{C}-$ & 3.5 \\
\hline Physical fitness & $\mathrm{F}$ & 2 & $\mathrm{D}$ & 3 \\
\hline Sleep & NA & NA & INC & INC \\
\hline Overweight and obesity & $\mathrm{F}$ & 2 & D- & 2.5 \\
\hline Inclusion & NA & NA & INC & INC \\
\hline Family and peers & $\mathrm{D}$ & 3 & $\mathrm{~F}$ & 2 \\
\hline School environment & $\mathrm{D}$ & 3 & $\mathrm{D}$ & 3 \\
\hline Community and environment & $\mathrm{C}$ & 4 & B & 5 \\
\hline Government strategies and investments & $\mathrm{C}$ & 4 & $\mathrm{~B}-$ & 4.5 \\
\hline
\end{tabular}

Abbreviation: PA, physical activity. Note: The letter grading system was defined as follows: A is $81 \%$ to $100 \%$; B is $61 \%$ to $80 \%$; $\mathrm{C}$ is $41 \%$ to $60 \%$, D is $21 \%$ to $40 \%$; $\mathrm{F}$ is $0 \%$ to $20 \%$; INC is incomplete data; NA: not applicable, as this indicator was not included in the current version. The Chilean numerical grading system was defined as 1 is $0 \%$ to $20 \%, 2$ is $21 \%$ to $35 \%, 3$ is $36 \%$ to $50 \%, 4$ is $51 \%$ to $60 \%, 5$ is $61 \%$ to $75 \%, 6$ is $76 \%$ to $90 \%$, and 7 is $91 \%$ to $100 \%$. In the Chilean numerical system, scoring under 4 denotes failure. In the case of negative outcomes such as sedentary behavior, and overweight and obesity, a reversed order of the percentages was considered for grading.

In the Global Matrix 3.0, the leading country was Denmark (A-). Chile performed particularly low in this domain, and only China and Taiwan scored as low as Chile, while $81 \%$ of the countries had higher grades than Chile. Also, the average grades of all groups of countries were higher than the one obtained by Chile in this domain (all countries averaged a grade of $\mathrm{C}$, the low and medium HDI countries earned a $\mathrm{C}$, the high HDI countries earned a D+, and very high HDI countries earned a $\mathrm{C}+$ ).

\section{Active Play}

Active play was graded as INCOMPLETE. Although 3 national surveys collected play-related data, none of them reported on the proportion of children and adolescents engaging in structured or nonstructured active or outdoor play during a day or week. ${ }^{18,24,30}$ The National Survey of Early Childhood 2010 (ENPI) only reported the most frequent environments where children play and the prevalence of parents who used to play with their children or take them to play with their peers. ${ }^{30}$ Similarly, the National Survey of Activities of Children and Adolescents 2012 (EANNA 2012) showed that $40.7 \%$ of adolescents engaged in outdoor sports or PA aside from physical education classes; however, the specific duration and frequency of these behaviors remain unknown. ${ }^{18}$ Finally, the National Vulnerability Survey 2017 explored whether the adolescents' homes were located near public recreational areas that allowed for recreational or physical activities and how frequently the students engaged in any of these activities. ${ }^{24}$ Nevertheless, as both activities were asked together in one question, a disaggregated analysis for recreational activities only, based on this question, was precluded. Despite the relevance of active playing, ${ }^{31}$ not only for physical but also for emotional and cognitive development, 28 other countries (57\%) also lacked data for grading this domain. ${ }^{10}$ Out of 20 countries that provided active play grades, 4 of them based their grades on expert opinion. The countries with the highest grades (B) were The Netherlands and Ethiopia. Although very dissimilar contexts may explain the high grades in both countries, the findings suggest that economic resources may not be as crucial to stimulate play as urban policies or cultural aspects could be. This is the second Chilean RC and, yet again, Chile did not receive a grade for this domain. This shows that its relevance has been underrated and highlights the urgent need to bring public and political attention to it, given its implications for children's physical and mental health.

\section{Active Transportation}

The score assigned for active transportation was F, or 2. This score was based on the following 4 aspects: (1) the proportion of children and adolescents who reported using active transportation (walking or cycling) during the journey to/from school ranged between $8.9 \%$ and $32.2 \% 20,32,33$; (2) a survey conducted in $n=323$ participants found that only $18.1 \%$ of adolescents use active transportation daily 20 ; (3) of those children who regularly walk to their schools, $11.4 \%$ were boys and $6.4 \%$ were girls, ${ }^{20}$ and $8.1 \%$ and $5.3 \%$ of these children belong to low-middle and high socioeconomic levels, respectively ${ }^{20}$; and (4) there was a lack of transportation data available for children aged under 12 years. In the Global Matrix 3.0, active transportation was the domain with the highest participation (48 out of 49 countries graded this domain), and active transportation was the single domain where none of the groups of countries (neither low HDI, medium and high HDI, nor very high HDI) averaged less than C-. Only Qatar did not grade this domain, due to the lack of relevance, because of the high temperatures that children are exposed to. Chile was the country with the lowest grade of the matrix in contrast to Japan, Nepal, and Zimbabwe, which earned an A-. Active travel is an inexpensive and efficient way of accumulating daily PA. ${ }^{34}$ Therefore, attention should be paid to potential barriers, such as unfriendly planning for walkers and cyclists, unsafe environments, and parents' motor dependency, which may be preventing children from undertaking active modes of transportation. 


\section{Sedentary Behaviors}

The grade of "C-" assigned to sedentary behaviors in children and adolescents was based on the following 4 criteria: (1) the prevalence of children (overall: $30.9 \%$, boys: $37.7 \%$ and girls: $24.0 \%)^{35}$ and adolescents $\left(44.97 \%^{36}\right.$ to $82.4 \%{ }^{23}$ ) spending $\geq 2$ hours in sedentary behavior (ie, screen time); (2) disparities in time spent in sedentary behavior between males and females-males were more likely to spend $\geq 2$ hours in sedentary behavior than females during early adolescence, ${ }^{35}$ but in late adolescence, females spent more time in sedentary behavior than males ${ }^{23}$; (3) lack of national data on sedentary behavior in children aged 5-10 years old and lack of published data using device-measured sedentary behavior; and (4) lack of initiatives aimed at reducing the time children and adolescents spend in sedentary behavior. Out of the other 45 countries that graded this domain, 10 of them (22\%) also scored a $\mathrm{C}-$. Along with active play, this was the domain with the lowest overall average (D+). Eight countries (17\%) scored higher than Chile, and amongst them, Bangladesh scored the highest (A-). Chile had a higher grade for sedentary behavior than the average showed by the high HDI group (D) and similar to the very high HDI group (D+). However, the low and medium HDI group (Botswana, Ethiopia, Ghana, India, Nepal, Nigeria, South Africa, and Zimbabwe) earned a higher grade than Chile $(\mathrm{C}+)$. This may suggest that the high use of electronic devices and increased indoor time, both factors that are coupled with economic development and high degrees of urbanization, may be hindering children's opportunities to be active. Therefore, a budget needs to be allocated to fund long-term programs capable of compensating for and modifying these detrimental structural factors that hamper children's opportunities to be active.

\section{Physical Fitness}

The grade of "D" assigned to physical fitness was based on the results from The National Study of Physical Education $2015,{ }^{21}$ using sex-age-specific international cut-off points assessed with the 20-m shuttle run test. ${ }^{37}$ The assessment criteria were as follows: (1) the average $\mathrm{VO}_{2}$ peak of sex and age percentile achieved for adolescents aged 13-15 years was $44 \%$ and 33\% in boys and girls, respectively; (2) the percentage of adolescents achieving a satisfactory level of cardiorespiratory fitness (ie, $>20$ percentile) was $62.3 \%$ and $58.1 \%$ in boys and girls, respectively; (3) lack of regular assessment of fitness in children and adolescents at the national level ${ }^{28}$; and (4) lack of national data on fitness levels in children (ie, 5-12 y old). However, a regional study that reported handgrip strength in 2026 children aged 8-12 years (nonrepresentative) showed that Chilean children scored higher than their South American counterparts from Colombia and Peru, but showed lower handgrip strength than European and Australian children. Physical fitness was included for the first time in the Global Matrix. About 55\% of the participant countries graded this indicator as INCOMPLETE; most of them were in the groups of low and medium HDI and high HDI. Within the group of very high HDI, Chile graded fitness substantially lower than Japan, the overall leader country in this domain (A), and equal to the average of the high HDI countries, although better grades were observed for $63 \%$ of the Global Matrix 3.0 participant countries.

\section{Sleep}

A grade of INCOMPLETE was assigned to sleep because no national data were available for the young Chilean population. Two regional cross-sectional studies reported information about the amount or quality of sleep in Chilean children ${ }^{38}$ and adolescents. ${ }^{39}$ These indicated that, overall, children aged 6-11 years old from Santiago de Chile slept fewer hours than recommended (ie, $10 \mathrm{~h}$ ) during the week (49.9\%) and weekend (16.7\%). ${ }^{38}$ Adolescents girls (9.2\%) from the "El Maule" region showed the worst sleep quality compared with boys $(5.5 \%)$, using the Sleep Self-Reported questionnaire. ${ }^{39}$ Therefore, representative national data are required to confirm the findings about the amount and quality of sleep. Studies have shown significant associations of sleep to health outcomes, such as adiposity, emotional regulation, and cognition. ${ }^{40}$ Sleep has also recently gained relevance given the interest on how diverse movement-related behaviors interact to affect general health, which has influenced the elaboration of the Canadian 24-hour movement guidelines. ${ }^{41}$ However, sleep has not yet been included within core indicators of the Global Matrix. Since children's overall health relies upon both active and nonactive behaviors, the INCOMPLETE grade assigned to sleep in Chile should be interpreted as a call for attention to implement surveillance.

\section{Overweight and Obesity}

The grade of D- in overweight and obesity was based on the following 5 criteria: (1) the national prevalence of being overweight in children (26\%) and adolescents (30\%), and obese children (22\%) and adolescents $(16 \%)^{22},(2)$ a higher prevalence of obesity in boys than in girls ${ }^{39,42-45}$ and a higher prevalence in rural than urban locations ${ }^{22}$, (3) most of the research being conducted in public schools and the central zone of the country $39,42,43,45$, (4) a lack of data on toddlers and in high-socioeconomic-status families, and (5) despite a small reduction in overweight and obesity in children compared with the previous national report, the prevalence of malnutrition in children and adolescents is still alarming. ${ }^{22}$

\section{Inclusion}

For this version, the indicator called "inclusion" was added. The following 3 specific groups were added to the indicator: (1) children with disability, (2) immigrant children, and (3) children from indigenous ethnic groups. Given the benchmarks shown in Table 1, not enough data were available, and consequently, an INCOMPLETE was assigned.

For the subgroup of "children with disability," no specific information on children's PA or sports participation was found. However, in the National Disability Study 2015, ${ }^{46} 20.5 \%$ of Chilean people with disabilities engaged in PA or sports for at least 30 minutes per week in their leisure time. However, these results are not differentiated between children and adults or between types of activities and sports. Regarding public policies and programs, information was found in the National Policy on Physical Activity and Sports 2016-2025 ${ }^{47}$ and in Law 20.978, which officially recognize the existence of adapted and Paralympic sports. ${ }^{48}$ In addition, some institutions have created their programs related to Adapted Sports, such as Teleton (foundation with rehabilitation centers for children) and Pedro Aguirre Cerda National Rehabilitation Institute. However, no data were found on the number of children participating in these programs. ${ }^{29}$

Regarding the "immigrant children" subgroup, no published information was found. Only one project by the Sports Observatory of the Universidad de Los Lagos was identified, entitled "Influence of the Values Linked to the Physical Sports Practice of Latin American Immigrants in Chile in Vulnerable School Communities," but no official results have yet been released.

For the "children belonging to indigenous ethnic" group, some studies were found, mainly in the Araucania region (Mapuche 
population), but their sample size limited representativeness. ${ }^{49,50}$ At the level of public policies, the National Sports Institute implemented in 2015 a program called "Sport in Ancestral People," whose goal is to promote and develop public policies aimed at promoting PA, applying an intercultural approach, and rescuing ancestral sports. ${ }^{47}$ From 2015 to 2017 , the number of regions included in the program increased from 8 to 14 regions, reaching 8600 participants (children and adults) in 2017 with an annual budget of about US\$300,000. ${ }^{29}$

\section{Family and Peers}

The grade $\mathrm{F}$ assigned to family and peers was based on 2 criteria. First, the percentage of adults over 18 years old who participate in any sports organization ranged from $5.9 \%$ to $16.5 \%$ in $2015 .{ }^{19,51}$ The Vulnerability Survey (2017) showed that only $12.6 \%$ of families of children in their first elementary grade $(\sim 6 \mathrm{y}$ old $)$ and $12.8 \%$ of families of children in their first year of high school belonged to a sports $\mathrm{club}^{24}$; second, only $13.3 \%$ of adults engage in leisure PA for 30 minutes 3 or more times per week, according to the National Health Survey 2016-2017. ${ }^{23}$ The results from the National Survey on Physical Activity and Sports (2015) showed that $19.9 \%$ of adults engaged in leisure PA using the same definition as above. ${ }^{51}$ No information was found on family members who were physically active with their kids nor on the percentage of children and adolescents who support friends and peers to be physically active. Regarding the RCs of other countries, only Ghana and Ethiopia obtained an F. A large number received an INC grade ( 22 countries, $45 \%$ ), while a similar number earned grades between a $\mathrm{C}$ and $\mathrm{D}$ (18 out of 27 countries). These results highlight the need for developing instruments able to provide valid and comparable data about the support of family and peers.

\section{School Environment}

The grade of D assigned to the school environment was based on the following 3 criteria: (1) PE participation: $12.8 \%$ to $33.0 \%$ of the adolescents indicated that they have PE 3 or more days per week, without differences in gender ${ }^{3,17}$; (2) the influence of teachers on adolescents' PA, as only $26 \%$ of the students indicated that they get positive reinforcement from their teachers for being physically active $^{52}$; and (3) only half of the schools $(52 \%)$ carry out activities that promote PA. ${ }^{29}$ In summary, Chile lacks national or regional data to assess relevant school environment indicators, such as school infrastructure for PA, the degree of compliance of PE classes per statutory obligations, or the percentage of schools that offer PA opportunities (excluding PE). These would provide a better understanding of the quality of the PA opportunities schools provide, and if appropriately monitored, they may contribute to improving government programs and the allocation of resources. The vast majority of countries scored their schools higher than Chile $(81 \%)$, and this was the only domain where more than a single country earned an A (Finland, Portugal, and Slovenia). Chile and Portugal are similar regarding economic and developmental indicators, such as HDI, life expectancy at birth, mean years of schooling, and gross national income per capita. ${ }^{53}$ However, Portugal radically differed regarding the school domain grade, and they also differed concerning the Gini index (Chile: 47.7 and Portugal: 35.5$).{ }^{54}$ This may reflect how public policies implemented through schools may be being negatively impacted by inequalities and highlights the structural challenges required for achieving progress.

\section{Community and Environment}

The grade of B assigned to community and environment was based on the following 4 criteria: (1) $39.0 \%$ to $55.0 \%$ of adolescents reported good/very good availability of parks, green spaces, cycling infrastructure, or sporting facilities ${ }^{19}$; (2) about $75 \%$ of children and adolescents reported having a public space for recreation nearby ${ }^{24}$; (3) $61.5 \%$ of adolescents reported normal or high level of safety in streets ${ }^{25}$; and (4) information was obtained at a national level, mostly from adolescents aged 15 and above, lacking information from other age groups. ${ }^{19,20,25}$

Seven countries (19\%) graded this domain higher than Chile, while the same number scored equally. Sweden achieved the highest grade (A), followed by Australia (A-). Chile scored as high as the average of the countries categorized as very high HDI (B-), while the low and medium, as well as the high HDI groups, averaged a D. This should be interpreted with caution, given the limited sources used for grading this domain.

\section{Government Strategies and Investment}

The grade of "B-" for government strategies and investment was based on the following 5 criteria: (1) the development of the new "National Policy for Sports and Physical Activity 2016-2025" coordinated by the Ministry of Sports, Ministry of Health, and Ministry of Education and launched at the end of $2016^{47}$; (2) after the launch of the new PA policy, a strategic plan was designed for the implementation and funding of different key areas ${ }^{55}$; (3) there is a lack of dissemination of the PA policy in other ministries, municipalities, and overall population; (4) undergoing PA national programs is mainly based and funded by the Ministry of Sports, leading to strategies with a strong focus on sports; (5) the annual budget of the Ministry of Sports was reduced consecutively every year from 2016 to 2018 from US\$221 million to US\$190 million (approximately $0.06 \%$ of the gross domestic product),${ }^{56-58}$ and this budget is mostly oriented to infrastructure and elite athletes (about $37 \%)^{59}$; and (6) the Declaration of the National Day of Sport for the Development and Peace on the 6th of April ${ }^{60}$ and the launch of a communicational campaign for PA promotion called "Women there are no limits." 29 Grading for this indicator was mostly based on expert opinions, as no benchmark was suitable for most criteria. Out of the other 41 countries that graded this domain, $37 \%$ scored higher than Chile. Slovenia and Finland led with the same grade (A), followed by Denmark (A-). Conversely to Slovenia, who earned an A- in the overall PA domain, the grades assigned to Finland and Denmark for overall PA were relatively low (D and $\mathrm{D}-$, respectively). This suggests that there might be a considerable gap between high-quality policies and governmental strategies and how they are finally implemented and received by the population of children. This should serve as a lesson, since Chile is precisely facing the policy implementation stage, and these findings suggest that translation from high-standard policies to desired PA indicators may require additional or more complex intermediate strategies.

As a summary, Chile only approved 2 indicators: community and environment, and government, and failed the other 8 domains that were being evaluated. The Chilean all-domain average grade was D, the lowest of the Global Matrix 3.0. Although Chile has been categorized within the very high HDI group, the grade of D was shared with India, Lebanon, Venezuela, Uruguay, Ecuador, and the United States, all of them categorized as medium to high HDI, except for the last. This may suggest that inequalities may affect PA-related behaviors and their sources of influence to a more considerable extent than the HDI. 
The HDI was used in the Global Matrix 3.0 to group the countries according to their development stage. As this index is heavily influenced by the gross national income per capita, which does not account for inequalities, Chile was mostly compared with European and Anglo-American countries. The Inequality-Adjusted Human Development Index ${ }^{61}$ could serve as a more suitable tool for categorizing when comparing countries with resembling development contexts.

Although establishing longitudinal comparisons between the 2016 and 2018 Chilean RCs may seem straightforward, we refrained from doing so since the observed differences are likely a result of the use of different data sources and modifications on the grading criteria. A suitable instrument and study design, capable of assessing various domains in a representative manner, would be required for this purpose. Otherwise, the Chilean RCs will continue being a cross-sectional effort that relies on a wide range of national surveys whose questions tend to change, and the delivery timeframes vary due to bureaucracy and political will. The latter also challenges the biennial basis of the Global Matrices, which may accommodate northern countries but are overly brief for gathering enough updated evidence in Chile and possibly the global south.

If no national surveillance system capable of capturing most RC domains is implemented by the next Global Matrix (2021), national research should seek to provide indicators on the quality of the data supporting future grades. These indices should mirror the data quality regarding, at least, geographic, socioeconomic, and age-range representativeness. Reporting on the longitudinal comparability of each domain's grades would also be desirable to better understand if progress or regression is occurring.

\section{Strengths and Limitations}

This RC was based on a large variety of sources, including large and nationally representative data sets. For the development of the current $\mathrm{RC}$, we included experts from different institutions, and we had extensive support from professionals of different government departments that provided updated information about the last national surveys, which may help for this objective. As we had access to most original data sets, we conducted ad-hoc analyses based on the indicators and benchmarks. As the national data on PA indicators were based on self-reported methods, the PA estimates may be prone to an overestimation of overall PA and an underestimation of sedentary behavior due to potential self-reporting bias. In addition, indicators such as overall PA, active transportation, sedentary behavior, and fitness were obtained from available studies and surveys on adolescents aged 12-17 years, leading to an underrepresentation of children under 12 due to the lack of evidence for this age group. Thus, as adolescents are more independent, the score assigned to active transportation to and from school may misrepresent a potential lower prevalence of active travel in children, ${ }^{62}$ given the potential dependency of their parents on private and public motor vehicles to take them to school and then commuting to work. Conversely, as PA decreases with age, ${ }^{63}$ having indicators such as PA, sedentary behavior, and fitness obtained uniquely from adolescents may result in more pessimistic scores than what would have been obtained if children of younger ages were appropriately surveyed.

\section{Conclusions}

Overall, Chile's grades were low. On the positive side, there is progress in the environmental and policy aspects. Attention should be paid to promoting active transportation and supporting families and peers to promote PA through culturally appropriate strategies, bearing in mind both the high levels of urbanization and digital penetration, as well as critical socioeconomic inequalities. Active play, sleep, and inclusion could not be evaluated, given the lack of data. We call the Chilean authorities and academic community to consider these topics when future surveys and studies related to children's health and healthy development are designed. Our findings indicate that the implementation of new strategies should be developed through collaboration between different sectors to maximize political opportunities and effective investments for increasing PA and decreasing sedentary time among children and young people in Chile.

\section{Acknowledgments}

We thank the participation of the advisory and collaborative committee: Matias Portela (Ministry of Health [MINSAL]), Gilda San Martin (Ministry of Sports), Andrea Vio Toro (JUNAEB), Fernando Concha (JUNAEB), and Patricio Roman (MINSAL). We also thank the collaboration of the UFRO Communications Office (DIRCOM), Universidad de La Frontera for the dissemination and media strategy. This work was supported by CONICYT FONDECYT 2016 11160720, DIUFRO DFP18-0022, and the Research Directorate, Universidad de La Frontera. NAF and ACO conceived and designed the manuscript. NAF and ACO drafted the manuscript. All authors analyzed and interpreted the data sources. All authors provided critical review and feedback for the manuscript. The authors have no conflicts of interest to disclose.

\section{References}

1. Okely AD, Tremblay MS, Reilly JJ, Draper CE, Bull F. Physical activity, sedentary behaviour, and sleep: movement behaviours in early life. Lancet Child Adolesc Health. 2018;2(4):233-235. PubMed ID: 30169293 doi:10.1016/S2352-4642(18)30070-1

2. Guthold R, Stevens GA, Riley LM, Bull FC. Worldwide trends in insufficient physical activity from 2001 to 2016: a pooled analysis of 358 population-based surveys with 1.9 million participants. Lancet Glob Health. 2018;6(10):e1077-e1086. PubMed ID: 30193830 doi:10.1016/S2214-109X(18)30357-7

3. Aguilar-Farias N, Martino-Fuentealba P, Carcamo-Oyarzun J, et al. A regional vision of physical activity, sedentary behaviour and physical education in adolescents from Latin America and the Caribbean: results from 26 countries. Int J Epidemiol. 2018;47(3):976-986. PubMed ID: 29554308 doi:10.1093/ije/dyy033

4. Aguilar-Farias N, Martino-Fuentealba P, Infante-Grandon G, Cortinez-O'Ryan A. Inactividad física en Chile: debemos responder al llamado global. Revista medica de Chile. 2018;145(12):1631-1632.

5. Varela AR, Pratt M, Powell K, et al. Worldwide surveillance, policy, and research on physical activity and health: the global observatory for physical activity. J Phys Act Health. 2017;14(9):701-709. PubMed ID: 28513338 doi:10.1123/jpah.2016-0626

6. World Health Organization. Global Action Plan on Physical Activity 2018-2030: More Active People for a Healthier World. Geneva, Switzerland: World Health Organization; 2018.

7. Rutter H, Cavill N, Bauman A, Bull F. Systems approaches to global and national physical activity plans. Bull World Health Organ. 2019;97(2):162-165. PubMed ID: 30728623 doi:10.2471/BLT.18. 220533

8. Tremblay MS, Gray CE, Akinroye K, et al. Physical activity of children: a Global Matrix of grades comparing 15 countries. J Phys Act Health. 2014;11(suppl 1):S113-S125. doi:10.1123/jpah.2014-0177 
9. Tremblay MS, Barnes JD, Gonzalez SA, et al. Global Matrix 2.0: report card grades on the physical activity of children and youth comparing 38 countries. J Phys Act Health. 2016;13(11)(suppl 2): S343-S366.

10. Aubert S, Barnes JD, Abdeta C, et al. Global Matrix 3.0 physical activity report card grades for children and youth: results and analysis from 49 countries. J Phys Act Health. 2018;15(suppl 2): S251-S273.

11. Aguilar-Farias N, Cortinez-O'Ryan A, Sadarangani KP, et al. Results from Chile's 2016 report card on physical activity for children and youth. J Phys Act Health. 2016;13(11)(suppl 2):S117-S123.

12. Aubert S, Barnes JD, Aguilar-Farias N, et al. Report card grades on the physical activity of children and youth comparing 30 very high human development index countries. J Phys Act Health. 2018; 15(suppl2):S298-S314.

13. Gonzalez SA, Barnes JD, Abi Nader P, et al. Report card grades on the physical activity of children and youth from 10 countries with high human development index: Global Matrix 3.0. J Phys Act Health. 2018;15(suppl 2):S284-S297. doi:10.1123/jpah.20180391

14. Manyanga T, Barnes JD, Abdeta C, et al. Indicators of physical activity among children and youth in 9 countries with low to medium human development indices: a Global Matrix 3.0 paper. J Phys Act Health. 2018;15(suppl 2):S274-S283. doi:10.1123/jpah. 2018-0370

15. Aguilar-Farias N, Miranda-Marquez S, Sadarangani KP, et al. Results from Chile's 2018 report card on physical activity for children and youth. $J$ Phys Act Health. 2018;15(suppl 2):S331-S332.

16. Schranz N, Olds T, Cliff D, et al. Results from Australia's 2014 report card on physical activity for children and youth. J Phys Act Health. 2014;11(suppl 1):S21-S25. doi:10.1123/jpah.2014-0164

17. Organisation for Economic Co-Operation and Development. PISA 2015 results (Volume III): Students' well-being. Paris: PISA, OECD Publishing; 2017. doi:10.1787/9789264273856-en

18. Ministerio de Desarrollo Social, Gobierno de Chile. Encuesta de Actividades de Niños, Niñas y Adolescentes 2012 (EANNA 2012). 2013. http://observatorio.ministeriodesarrollosocial.gob.cl/ layout/doc/eanna/Manual_cuestionario_EANNA.pdf. Accessed May 05, 2020.

19. Ministerio de Salud, Gobierno de Chile. Encuesta Nacional de Calidad de Vida 2015-2016 (ENCAVI) 2015-2016. 2017. https:// www.minsal.cl/wp-content/uploads/2017/02/PRESENTACIONENCAVI-2016-11.02.2017.pdf. Accessed May 05, 2020.

20. Ministerio de Vivienda y Urbanismo, Gobierno de Chile. Encuesta de Percepción de Calidad de Vida Urbana (EPCVU 2015). 2016. https:// calidaddevida.minvu.gob.cl/documentos-encuesta-de-percepcion-decalidad-de-vida-urbana/. Accessed May 05, 2020.

21. Agencia de Calidad de la Educacion Chile. Estudio Nacional de Educación Física 2015 (ENEF). 2016. https://www.agencia educacion.cl/estudios/estudio-de-educacion-fisica/. Accessed May 05, 2020.

22. Junta Nacional de Auxilio Escolar y Becas (JUNAEB). Informe Mapa Nutricional 2017. 2018. https://www.junaeb.cl/mapa-nutricional/. Accessed May 05, 2020.

23. Ministerio de Salud, Gobierno de Chile. Encuesta Nacional de Salud (ENS) 2016-2017. 2018. http://epi.minsal.cl/encuesta-ens/. Accessed May 05, 2020.

24. Junta Nacional de Auxilio Escolar y Becas (JUNAEB). Encuesta de Vulnerabilidad 2017 (EV 2017). 2018. https://www.junaeb.cl/ encuestas-vulnerabilidad. Accessed May 05, 2020.

25. Ministerio del Interior y Seguridad Pública de Chile. Encuesta Nacional Urbana de Seguridad Ciudadana 2016 (ENUSC). 2017. http://www.seguridadpublica.gov.cl/encuestas/encuesta-nacionalurbana-de-seguridad-ciudadana-2016/. Accessed May 05, 2020.

26. Colley RC, Brownrigg M, Tremblay MS. A model of knowledge translation in health: the active healthy kids Canada report card on physical activity for children and youth. Health Promot Pract. 2012;13(3):320-330. PubMed ID: 22447666 doi:10.1177/ 1524839911432929

27. Barnes JD, Tremblay MS. Changes in indicators of child and youth physical activity in Canada, 2005-2016. Can J Public Health. 2017;107(6):e586-e589. doi:10.17269/cjph.107.5645

28. Garcia-Hermoso A, Cofre-Bolados C, Andrade-Schnettler R, et al. Normative reference values for handgrip strength in Chilean children at 8-12 years old using the empirical distribution and the Lambda, Mu, and Sigma statistical methods [published online ahead of print May 30, 2018]. J Strength Cond Res. doi:10.1519/JSC. 0000000000002631

29. Ministerio del Deporte, Gobierno de Chile. Cuenta Publica Participativa 2018. 2018.

30. Junta Nacional de Jardines Infantiles (JUNJI). Encuesta Nacional de Primera Infancia, ENPI 2010. 2010. http://www.crececontigo. /gob.cl/wp-content/uploads/2015/12/Informe-Final-Preliminar-PrimeraENCUESTA-NACIONAL-DE-PRIMERA-INFANCIA.pdf. Accessed May 05, 2020.

31. Isenberg JP, Quisenberry N. A position paper of the association for childhood education international PLAY: essential for all children. Child Educ. 2002;79(1):33-39. doi:10.1080/00094056.2002. 10522763

32. Garcia-Hermoso A, Saavedra JM, Olloquequi J, Ramirez-Velez R. Associations between the duration of active commuting to school and academic achievement in rural Chilean adolescents. Environ Health Prev Med. 2017;22(1):31. PubMed ID: 29165126

33. Rodriguez-Rodriguez F, Cristi-Montero C, Celis-Morales C, Escobar-Gomez D, Chillon P. Impact of distance on mode of active commuting in Chilean children and adolescents. Int J Environ Res Public Health. 2017;14(11):E1334.

34. Cooper AR, Jago R, Southward EF, Page AS. Active travel and physical activity across the school transition: the PEACH project. Med Sci Sports Exerc. 2012;44(10):1890-1897. PubMed ID: 22525779 doi:10.1249/MSS.0b013e31825a3a1e

35. Aguilar MM, Vergara FA, Velasquez EJ, Marina R, Garcia-Hermoso A. Screen time impairs the relationship between physical fitness and academic attainment in children. J Pediatr. 2015;91(4):339-345. doi:10.1016/j.jped.2014.10.004

36. Barja Yanez S, Arnaiz Gomez P, Villarroel Del Pino L, et al. Dyslipidemias in school-age Chilean children: prevalence and associated factors. Nutr Hosp. 2015;31(5):2079-2087. PubMed ID: 25929377

37. Tomkinson GR, Lang JJ, Tremblay MS, et al. International normative $20 \mathrm{~m}$ shuttle run values from 1142026 children and youth representing 50 countries. Br J Sports Med. 2017;51(21):1545-1554. PubMed ID: 27208067 doi:10.1136/bjsports-2016-095987

38. Agüero SD, Rivera PH. Association between the amount of sleep and obesity in Chilean school children. Arch Argent Pediatr. 2016; 114(2):114-119.

39. García-Hermoso A, Aguilar MM, Vergara FA, Velásquez EJ, Marina R. Obesity, cardiorespiratory fitness, and self-reported sleep patterns in Chilean school-aged children. Behav Sleep Med. 2017;15(1):7080. PubMed ID: 26645094 doi:10.1080/15402002.2015.1083023

40. Chaput J-P, Gray CE, Poitras VJ, et al. Systematic review of the relationships between sleep duration and health indicators in schoolaged children and youth. Appl Physiol Nutr Metab. 2016;41(6):S266S282. doi:10.1139/apnm-2015-0627 
41. Tremblay MS, Carson V, Chaput JP, et al. Canadian 24-hour movement guidelines for children and youth: an integration of physical activity, sedentary behaviour, and sleep. Appl Physiol Nutr Metab. 2016;41(6)(suppl 3):S311-S327.

42. Herrera JC, Lira M, Kain J. Vulnerabilidad socioeconómica y obesidad en escolares chilenos de primero básico: comparación entre los años 2009 y 2013. Rev Child Pediatr. 2017;88(6):736-743. doi:10. 4067/S0370-41062017000600736

43. Lizana PA, Gonzalez S, Lera L, Leyton B. Association between body composition, somatotype and socioeconomic status in Chilean children and adolescents at different school levels. J Biosoc Sci. 2018;50(1):53-69. PubMed ID: 28238292 doi:10.1017/ S0021932017000025

44. Cigarroa I, Sarqui C, Palma D, et al. Estado nutricional, condición física, rendimiento escolar, nivel de ansiedad y hábitos de salud en estudiantes de primaria de la provincia del Bio Bío (Chile): Estudio transversal. Revista chilena de nutrición. 2017;44(3):209-217. doi: 10.4067/S0717-75182017000300209

45. Caamaño Navarrete F, Delgado Floody P, Jerez Mayorga D, Osorio Poblete A. Bajos niveles de rendimiento físico, VO2MAX y elevada prevalencia de obesidad en escolares de 9 a 14 años de edad. Nutrición Hospitalaria. 2016;33(5):1045-1051. PubMed ID: 31937106

46. Ministerio de Desarrollo Social, Gobierno de Chile. 2do Estudio Nacional de la Discapacidad en Chile 2015. Servicio Nacional de la Discapacidad. 2016. https://www.senadis.gob.cl/pag/355/1197/ ii_estudio_nacional_de_discapacidad. Accessed May 05, 2020.

47. Ministerio del Deporte, Gobierno de Chile. Política Nacional de Actividad Física y Deporte 2016-2025 (1st ed). Santiago, Chile; 2016.

48. Ministerio del Deporte, Gobierno de Chile. Ley 20978. Reconoce el deporte adaptado y paralímpico. Ministerio del Deporte, Gobierno de Chile; 2016. https://www.leychile.cl/Navegar?idNorma=1098002. Accessed May 05, 2020.

49. Carcamo-Araneda C, Ponce-Castro J, Carcamo-Oyarzun J, AguilarFarias N. Nivel de actividad física, conducta sedentaria y hábitos alimenticios según características etnográficas de adolescentes de Curacautín, Chile. Rev Arch Soc Chil Med Deporte. 2018;63(1):1-13.

50. Valdés-Badilla PA, Vergara-Coronado NY, Suazo-Poblete D, GodoyCumillaf A, Herrera-Valenzuela T, Durán-Agüero S. Perfil antropométrico y hábitos de actividad física de estudiantes Mapuches de una escuela rural de Temuco, Chile. Revista Española de Nutrición Humana y Dietética. 2015;19(1):28-35. doi:10.14306/renhyd.19.1.127

51. Ministerio del Deporte, Gobierno de Chile. Encuesta Nacional de Hábitos de Actividad Física y Deportes en la Población de 18 años y más. Informe Final. Santiago, Chile; 2016. http://www.mindep. cl/wp-content/uploads/2016/07/INFORME-FINAL-ENCUESTADEPORTES-COMPLETO_.pdf. Accessed May 05, 2020.
52. Olivares PR, Cossio-Bolanos MA, Gomez-Campos R, AlmonacidFierro A, Garcia-Rubio J. Influence of parents and physical education teachers in adolescent physical activity. Int J Clin Health Psychol. 2015;15(2):113-120. PubMed ID: 30487828 doi:10.1016/j.ijchp. 2015.01.002

53. United Nations Development Programme. 2018 Statistical Update: Human Development Indices and Indicators. New York; 2018. http:// hdr.undp.org/en/content/human-development-indices-indicators2018. Accessed May 05, 2020.

54. The World Bank. GINI Index (World Bank Estimate) Data. 2018. https://data.worldbank.org/indicator/SI.POV.GINI?view=map. Accessed May 05, 2020.

55. Ministerio del Deporte, Gobierno de Chile. Plan Estratégico Nacional de Actividad Física y Deporte 2016-2025. 2017. http://biblioteca. digital.gob.cl/handle/123456789/3594. Accessed May 05, 2020.

56. Ministerio de Hacienda, Gobierno de Chile. Ley de presupuestos del sector público Año 2018. 2017. https://www.dipres.gob.cl/597/ articles-172496_doc_pdf. Accessed May 05, 2020.

57. Ministerio de Hacienda, Gobierno de Chile. Ley de presupuestos del sector público Año 2017. 2016. http://www.dipres.gob.cl/598/ articles-149470_Ley_de_Presupuestos_2017_V2.pdf. Accessed May 05, 2020.

58. Ministerio de Hacienda, Gobierno de Chile. Ley de presupuestos del sector público Año 2016. 2015. http://www.dipres.gob.cl/598/ articles-135748_Ley_de_Presupuestos_2016.pdf. Accessed May 05, 2020.

59. Cortinez-O'Ryan A, Aguilar-Farias N. Nuevas políticas públicas para la promoción de la actividad física. In: Mardones F, Arnaiz Gomez P, Barja Yanez S, Rosso P, eds. Obesidad en Chile ¿Qué podemos hacer? Santiago, Chile: Ediciones Universidad Catolica de Chile; 2018:451-461.

60. Ministerio del Interior y Seguridad Pública, Gobierno de Chile. Ley 21007. Establece el 6 de abril de cada año como Día Nacional del Deporte para el Desarrollo y la Paz. Ley Núm. 21.007. 2017. https:// www.leychile.cl/Navegar?idNorma=1101587. Accessed May 05, 2020.

61. Hicks DA. The inequality-adjusted human development index: a constructive proposal. World Dev. 1997;25(8):1283-1298. doi:10. 1016/S0305-750X(97)00034-X

62. Chillón P, Ortega FB, Ruiz JR, et al. Active commuting to school in children and adolescents: an opportunity to increase physical activity and fitness. Scand J Public Health. 2010;38(8):873-879. doi:10. 1177/1403494810384427

63. Jago R, Salway R, Emm-Collison L, Sebire SJ, Thompson JL, Lawlor DA. Association of BMI category with change in children's physical activity between ages 6 and 11 years: a longitudinal study. Int J Obes. 2020;44(1):104-113. doi:10.1038/s41366-019-0459-0 